Abstracts of communications and poster presentations that have been presented on the occasion of the meeting of the FNRS-FRSM contact group

\title{
Cellular Mechanisms of Inflammation
}

held in Brussels, 17 September 1999

\section{Organized by Gérard Camus}

Centre de I'Oxygène, Recherche \& Développment, Institut de Chimie, Sart Tilman, 4000 Liège, Belgium

\section{The rejection of vascularized heart allograft by IL-5 secreting CD4 ${ }^{+} \mathrm{T}$ lymphocytes and eosinophils is regulated by $\mathrm{CD}^{+} \mathrm{T}$ cells and IFN- $\gamma$}

\section{Michel Y Braun ${ }^{1}$, Fabrice Desalle ${ }^{1}$, Alain Le Moine ${ }^{1}$, Sophie Van den Dungen ${ }^{1}$, Christian Noel ${ }^{1}$, Patrick Matthys ${ }^{2}$, Robert Kiss ${ }^{3}$ and Michel Goldman ${ }^{1}$ \\ ${ }^{1}$ Department of Experimental Immunology, ${ }^{3}$ Department of Histology, Free University of Brussels; ${ }^{2}$ REGA Institute, Catholic University of Leuven, Belgium}

Alloreactive IL-5-secreting $\mathrm{CD} 4^{+} \mathrm{T}$ lymphocytes were recently shown to mediate the rejection skin allografts and this process involved intragraft recruitment of eosinophils. Our study ex tends these observations to a model of vascularized heart allograft in the mouse. $\mathrm{BALB} / \mathrm{c}\left(\mathrm{H}-2^{\mathrm{d}}\right)$ hearts transplanted into $\mathrm{C} 57 \mathrm{BL} / 6\left(\mathrm{H}-2^{\mathrm{b}}\right)$ recipients have a median survival of 9 days. Contrarily to what is observed for skin rejection, the rejection of fully mismatched heart allografts is not characterized by intragraft eosinophilia and IL-5-secreting cells are not detected in the recipient's lymph nodes. We therefore analyzed the factors that might determine the development of an IL-5-mediated rejection response to heart allograft. $\mathrm{CD} 8^{\dagger} \mathrm{T}$ lymphocytes are know $n$ to inhibit the development of eosinophilia and IL-5 secretion in models of experimental allergic or viral asthma and in allograft rejection. We indeed confirmed these observations in our model as treatment of the recipient with depleting anti-CD8 antibodies induced intragraft eosinophilia. The eosinophilic infiltrates were dependent on the production in vivo of $\mathrm{IL}-5$ as depletion of $\mathrm{CD}^{+}$cells in IL5 -deficient recipients did not induce eosinophilia.
More importantly, the rejection of $B A L B / c$ hearts in these mice was significantly delayed (up to 20 days after grafting) compared with the rejection in untreated controls (9 days).

In in vitro experiments, the presence of $\mathrm{CD}^{+} \mathrm{T}$ cells in MLR of alloreactive $\mathrm{CD} 4^{+}$T cells inhibited IL-5 secretion. This inhibition was dependent on IFN $\gamma$ as adding neutralizing anti-IFN $\gamma$ antibodies to the MLR prevented the inhibition of IL-5 secretion. Moreover, the rejection of fully mismatched heart allografts by IFN $\gamma$-receptor (IFN $\gamma$ R)-deficient recipients was characterized by a massive intragraft eosinophilia. On the contrary, grafts from IFN $\gamma$-R-deficient recipients treated with neutralizing anti-IL-5 antibodies, did not exhibit eosinophil infiltration. This study demonstrates IL-5-secreting $\mathrm{CD}^{+} \mathrm{T}$ cells and eosinophils as effectors of the rejection of MHC class I- and IIdisparate heart allograft and reveals the importance of $\mathrm{CD} 8^{+} \mathrm{T}$ cells and IFN $\gamma$ in regulating this pathway of rejection.

\section{Endotoxaemia and plasma neopterin levels following a marathon race}

\section{G. Camus ${ }^{1}$, M. Nys, J. Duchateau, G. Deby-Dupont, C. Deby, M. Lamy and J. Poortmans}

${ }^{1}$ Research Associate, FNRS, Center of Oxygen, Research and Development, Institute of Chemistry, Sart Tilman, University of Liège, Belgium

To address the question of whether endotoxaemia accompanying long-term physical work could be involved in exercise-induced increase in plasma neopterin levels, 18 male marathon runners [mean age: 41 
\pm 2 (SEM) years] were studied. The occurrence of exercise-induced endotoxaemia was studied by the measurement of serum activity of $\operatorname{IgG}$ antibodies tow ard LPSs from various smooth $(n=13)$ and rough $(n=9)$ form bacterial strains. Based on the changes of the ELISA assay of IgG antibody activity to the various LPSs, the subjects were divided into two groups. It was assumed that subjects with a reduction of their $\operatorname{IgG}$ activity have been challenged with endotoxins; these subjects were assigned to group $1(n=12)$. The other volunteers were placed in group $2(n=6)$. Mean plasma neopterin concentrations measured at rest were practically equal in both groups (group $1: 2.00 \mathrm{pg} / \mathrm{ml}$; group $2: 2.02 \mathrm{pg} / \mathrm{ml}$ ). This variable increased significantly following ex ercise $(P<0.05)$, reaching peak values immediately after the end of the race in both groups and returned to values that did not differ significantly from baseline after $1 \mathrm{~h}$ recovery. The net increase in plasma neopterin levels $(\Delta$ Neopt $)$, defined as the difference between peak values and baseline were $0.37 \pm 0.02$ and $0.47 \pm$ $0.02 \mathrm{pg} / \mathrm{ml}$ (mean $\pm \mathrm{SEM}$ ) in groups 1 and 2, respectively. By unpaired Student's $t$-test, it w as found that the difference between these $\Delta$ Neopt was statistically significant $(P<0.05)$.

From these results, we concluded that the hypothetical role of endotoxaemia in exercise-induced increase in plasma neopterin concentration observed in our subjects was not substantiated by the present results.

\section{Nitric oxide induces apoptosis in human chondrocytes}

\section{J. Chahboune ${ }^{1}$, R. Greimer ${ }^{2}$, C. Humblet ${ }^{2}$, M-P. Defresne ${ }^{2}$, M. Mathy-Hartert ${ }^{1}$, \\ A. Labasse ${ }^{1}$, G. Deby ${ }^{3}$, J.M. Crielaard ${ }^{1}$, J.Y. Reginster ${ }^{1}$, Y. Henrotin ${ }^{1}$, \\ ${ }^{1}$ Bone and Cartilage Metabolism Research Unit; ${ }^{2}$ Department of Anatomopathology; ${ }^{3}$ Center for Oxygen Biochemistry, University of Liège, Belgium}

Nitric oxide (NO) was found to be elevated in the synovial fluid of patients with rheumatoid arthritis and osteoarthritis, suggesting its role in joint diseases pathophysiology. Moreover, $\mathrm{NO}$ was reported to be a mediator of the IL-1 $\beta$ effects responsible for cartilage degradation. Recently, it was suggested that NO is involved in cell apoptosis, and therefore could be an interesting target for drugs used in the treatment of joint diseases. For this purpose, we have developed a model of chondrocytes apoptosis induced by a $\mathrm{NO}$ donor.

Enzymatically isolated human chondrocytes were cultured for 24 hours in the absence or in the presence of Sodium NitroPrusside (SNP), which is an
NO donor. Apoptosis was analysed by flow cytometry (FACS), using Annexin-V-FLUO as marker. AnnexinV-FLUO is a $\mathrm{Ca}^{2+}$ dependent protein with high affinity for phosphatidylserine (PS) which is translocated from plasma membrane in the early stages of apoptosis. Propidium Iodide (PI) was also used to discriminate necrotic from apoptotic cells.

In the control conditions (w ithout SNP), 3\% of the chondrocytes were labelled with Annexin-V. When SNP $(100 \mu \mathrm{M})$ was added, the number of apoptotic chondrocytes reached $23 \%$, whereas the number of PI positive cells remained stable (5.8\%).

These findings suggest that $\mathrm{NO}$ donors induce apoptosis, and therefore could be involved in cartilage repair failure.

\section{In vitro effects of recombinant human interferon on basal and IL-1 $\beta$ stimulated stromelysin, proteoglycans, cytokines (IL-6, IL-8, IL-10), nitric oxide and IL-1ra in human chondrocytes}

\author{
J. Chahboune ${ }^{1}$, S.X. Zheng ${ }^{1}$, \\ M. Mathy-Hartert ${ }^{1}$, X. de Leval ${ }^{3}$, A. Labasse ${ }^{1}$, \\ G. Deby ${ }^{2}$, J.-M. Crielaard ${ }^{1}$, I.-Y. Reginster', \\ J.-M. Dogné ${ }^{3}$, J. Delarge ${ }^{3}$ Henrotin ${ }^{1}$ \\ ${ }^{1}$ Bone and Cartilage; Metabolism Research \\ Unit; ${ }^{2}$ Center for Oxygen Biochemistry; \\ ${ }^{2}$ Department of Medicinal Chemistry (3), \\ University of Liège, 4000 Liège, Belgium
}

Interferon $\gamma$ (IFN $\gamma$ ) is found to be elevated in the synovial fluid of patients with arthritis and osteoarthritis suggesting its implication in joint diseases pathogenesis. In this study, we investigated the effects of IFN $\gamma$ on the production of cytokines (IL-6, IL-8, IL$10)$, prostanglandin $\mathrm{E}_{2}\left(\mathrm{PGE}_{2}\right.$, proteoglycans $(\mathrm{PG})$, IL1 receptor antagonist (IL-1 ra) and stromelysin by unstimulated and IL-1 $\beta$ treated human chondrocytes. The role played by $\mathrm{PGE}_{2}$ and $\mathrm{NO}$ in the response of chondrocytes to IFN $\gamma$ were also examined using cyclooxygenase and NO synthase inhibitors.

Enzymatically isolated human chondrocytes were cultured for 48 hours in the absence or in the presence of IL-1 $\beta\left(10^{-11}\right.$ to $\left.10^{-10} \mathrm{M}\right)$, IFN $\gamma(0.1$ to $100 \mathrm{U} / \mathrm{ml})$, diclofenac $\left(10^{-5} \mathrm{M}\right)$, or $\mathrm{N}^{\mathrm{G}}$ monomethylL-arginine (L-NMMA'; $0.5 \mathrm{mM}$ ) added alone or in combination. IL-6, IL-8, IL-10, stromelysin and IL-1ra were detected by Enzyme Amplified Sensitivity Immunoassays (EASIAs). PG and $\mathrm{PGE}_{2}$ were quantified in the culture supernatants by a radioimmunoassay method (RIA). Nitric oxide production, detected as nitrite was quantified by a spectrophotometric method based on the Griess reaction.

As expected, proteoglycan production was strongly inhibited by IL-1 $\beta$ and stromelysin production highly stimulated. IL-1 $\beta$ also increased IL-6, IL-8, PGE 2 , IL-1 ra 
and IL-10 production by human chondrocytes. IFN $\gamma$ markedly inhibited the constitutive and IL-1 $\beta$-stimulated IL- 8 and IL- 10 productions but increased IL- 6 , IL$1 \mathrm{ra}$ and $\mathrm{PGE}_{2}$ synthesis. Furthermore, IFN $\gamma$ inhibited both PG and stromelysin produced by untreated and IL-1 $\beta$-treated chondrocytes. Neither diclofenac nor L-NMMA were able to markedly reverse IFN $\gamma$ effects.

These findings suggest that IFN $\gamma$ and IL-1 $\beta$ act synergically to stimulate the production of IL-6, IL-1 ra, $\mathrm{NO}$ and $\mathrm{PGE}_{2}$ and inhibit PG synthesis. By contrast, IL$1 \beta$ and IFN $\gamma$ have opposite effects on IL-8, IL-10 and stromelysin production.

\section{Comparative effects of a sulfonylcyanoguanidine (BM 557) and a sulfonylurea (BM 520) on interleukin 6 (IL-6), interleukin 8 (IL-8), prostaglandin $\mathrm{E}_{2}$ $\left(\mathrm{PGE}_{2}\right)$ and nitric oxide (NO) production by human articular chondrocytes}

\section{J.M. Dogné ${ }^{1}, X$. de Leval ${ }^{1}$, J. Delarge ${ }^{1}$,} G. Deby' ${ }^{2}$ M. Mathy ${ }^{3}$ J. Chahboune ${ }^{3}$,

A. Labasse ${ }^{3}$, P. Neven ${ }^{1}$, J.Y. Reginster ${ }^{3}$ and Y. Henrotin ${ }^{3}$

${ }^{1}$ Department of Medicinal Chemistry, University of Liège, 1 av. de I'Hôpital, tour 4 (+5) Sart-Tilman; ${ }^{2}$ Centre for the Biochemistry of Oxygen, Institute of Chemistry, Sart Tilman; ${ }^{3}$ Bone and Cartilage Metabolism Research Unit, University Hospital, Sart-Tilman, CHU-B23, 4000 Liège, Belgium

The aim of this study was to investigate the influence of the sulfonylcyanoguanidine moiety of BM 557 compared to the sulfonylurea moiety of BM 520 on human chondrocyte culture. Therefore, several parameters such as interleukin 6 (IL-6), interleukin 8 (IL$8)$, prostaglandin $\mathrm{E}_{2}\left(\mathrm{PGE}_{2}\right)$ and nitric oxide $(\mathrm{NO})$ production were evaluated. Chondrocytes were isolated from their ex tracellular matrix by triple successive enzymatic digestions of the cartilage and cultured for $48 \mathrm{~h}$ in a well-defined culture medium in the absence or in the presence of IL-1 $\beta$ and with or without the investigated drug (at $100 \mu \mathrm{M})$. IL-6 and IL8 were directly assayed into culture media by specific enzyme amplified sensitivity immunoassays. $\mathrm{PGE}_{2}$ was quantified by a specific radioimmunoassay. Cell culture media were assayed for $\mathrm{NO}_{2}$ using a spectrophotometric assay based upon the Griess reaction. In regard to the controls, BM 520 did not affect constitutive $\mathrm{PGE}_{2}$ production by chondrocytes but decreased by $57.24 \%$ IL- $1 \beta$ stimulated $\mathrm{PGE}_{2}$ production whereas BM 557 increased more than 10-times either unstimulated or IL-1 $\beta$-stimulated $\mathrm{PGE}_{2}$ production $\left[\times 15.2 \quad \mathrm{PGE}_{2}\right.$ and $\left.\times 12.5 \mathrm{PGE}_{2}(+\mathrm{IL}-1 \beta)\right]$. Moreover, BM 557 which reduced DNA content in the cellular phase [\% reduction: $37.9 \%$ (+IL-1 $\beta$ ): $44.3 \%$ ] strongly inhibited IL-6, IL-8 and NO production by unstimulated or IL-1 $\beta$-treated chondrocytes (\% of inhibition of IL-6 and IL-8 production > 99\%; \% of inhibition of NO production: $52.4 \%$ and + IL-1 $\beta$ : $53.3 \%)$. In the same conditions, BM 520 which did not affect DNA content also inhibited IL-6, IL-8 and NO production [\% of inhibition of IL-6: 54.8 and IL-6 (+IL$1 \beta): 59.7$; \% of inhibition of IL-8: 39.9 and IL-8 (+ IL$1 \beta$ ): 43.2]; \% of inhibition of NO: 13.3 and IL-6 (+IL$1 \beta):$ 8.22]. These results indicate that the sulfonylcyanoguanidine moiety of BM 557 is potentially toxic for chondrocytes compared to BM 520 which is an inhibitor of unstimulated or IL-1 $\beta$-treated IL-6, IL-8 and NO production without affecting DNA content of the cellular phase.

\section{Effects of BM 540 on interleukin 6 (IL-6), interleukin 8 (IL-8), prostaglandin $F_{2}\left(P E_{2}\right)$ and nitric oxide (NO) production by human articular chondrocytes}

\section{J.M. Dogné ${ }^{1}, X$. de Leval ${ }^{1}$, J. Delarge ${ }^{1}$,} G. Deby ${ }^{2}$, M. Mathy ${ }^{3}$, J. Chahboune ${ }^{3}$,

A. Labasse ${ }^{3}$, P. Neven ${ }^{1}$, J.Y. Reginster ${ }^{3}$ and Y. Henrotin ${ }^{3}$

${ }^{1}$ Department of Medicinal Chemistry, University of Liège, 1 av. de l'Hôpital, tour 4 (+5) Sart-Tilman; ${ }^{2}$ Centre for the Biochemistry of Oxygen, Institute of Chemistry, Sart Tilman; ${ }^{3}$ Bone and Cartilage Metabolism Research Unit, University Hospital, Sart-Tilman, CHU-B23, 4000 Liège, Belgium

Sulfonylurea BM 540 was investigated as thromboxane $A_{2}$ receptor antagonist and appeared to be slightly potent on this target. Deeper investigations were performed with this drug on human chondrocyte in culture. Several inflammatory mediators such as interleukin 6 (IL-6), interleukin 8 (IL-8), prostaglandin $\mathrm{E}_{2}\left(\mathrm{PGE}_{2}\right)$ and nitric oxide $(\mathrm{NO})$ production were evaluated. Chondrocytes were isolated from their extracellular matrix by triple successive enzymatic digestions of the cartilage and cultured for $48 \mathrm{~h}$ in a well-defined culture medium in the absence or in the presence of IL-1 $\beta$ and with or without BM 540 at the concentration of $100 \mu \mathrm{M}$. IL-6 and IL-8 were directly assayed into culture media by specific enzyme amplified sensitivity immunoassays. $\mathrm{PGE}_{2}$ was quantified by a specific radioimmunoassay. Cell culture media were assayed for $\mathrm{NO}_{2}$ using a spectrophotometric assay based upon the Griess reaction. In regard to the controls, BM 540 did not affect constitutive $\mathrm{PGE}_{2}$ production by chondrocytes but decreased by $48.5 \%$ IL-1 $\beta$-stimulated $\mathrm{PGE}_{2}$ production. Moreover, BM 540, which did not affect DNA content in the cellular phase, strongly inhibited IL-6 and IL-8 production by 
unstimulated or IL-1 $\beta$-treated chondrocytes [\% of inhibition of IL-6: 90.23 and IL-6 (+IL-1 $\beta$ ): 84.12 ; \% of inhibition of IL-8: 77.66 and IL-8 (+IL-1 $\beta$ ): 81.76]. In the same conditions, our drug also decreased $\mathrm{NO}$ production (30.22\% and with IL-1 $\beta$ 31.77\%). From these results, we conclude that BM 540 is a potent inhibitor of IL- 6 , IL- 8 and NO production by either unstimulated or IL-1 $\beta$-stimulated human chondrocytes. Moreover, BM 540 also inhibits IL-1 $\beta$-stimulated $\mathrm{PGE}_{2}$ production. Therefore, BM 540 could be an interesting drug for the treatment of joint diseases with potent antiinflammatory properties.

\section{In vitro induced imbalance between stromelysin and TIMP-1 production by human chondrocytes}

\section{X. de Leval ${ }^{1}$, J.M. Dogné ${ }^{1}$, J. Delarge ${ }^{1}$,}

G. Deby ${ }^{2}$, M. Mathy ${ }^{3}$, J. Chahboune ${ }^{3}$,

A. Labasse ${ }^{3}$, P. Neven ${ }^{1}$, J.Y. Reginster ${ }^{3}$ and

Y. Henrotin ${ }^{3}$

${ }^{1}$ Department of Medicinal Chemistry, University of Liège, 1 av. de I'Hôpital, tour 4 (+5) Sart-Tilman; ${ }^{2}$ Centre for the Biochemistry of Oxygen, Institute of Chemistry, Sart Tilman; ${ }^{3}$ Bone and Cartilage Metabolism Research Unit, University Hospital, Sart-Tilman, CHU-B23, 4000 Liège, Belgium

In cartilage, extracellular matrix integrity is maintained by a delicate balance between catabolic and anabolic processes controlled by grow th factors, cytokines, hormones and mechanical stimuli. In osteoarthritis, this equilibrium is disrupted, leading progressively to an excess of tissue degradation and finally, tissue disappearance. The imbalance between stromelysin and TIMPs production constitute an important physiopathological process. In this study, we have investigated the effects of TGF $\beta 1$, aceclofenac (ACE) and its main metabolites diclofenac and $4 \mathrm{OH}-\mathrm{aceclofenac}$ (DICLO and 4-OH ACE) on stromelysin synthesis and activity and TIMP-1 production by human chondrocytes. Chondrocytes were cultured for $72 \mathrm{~h}$ in the absence or in the presence of recombinant human IL-1 $\beta$ (rhIL-1 $\beta ; 2$ to $100 \mathrm{pg} / \mathrm{ml}$ ) either alone or in combination with human recombinant TGF $\beta 1(10 \mathrm{ng} / \mathrm{ml})$ and/or ACE, DICLO or $4-\mathrm{OH}$ ACE $(0.5,2$ and $10 \mu \mathrm{g} / \mathrm{ml})$. Stromelysin and TIMP-1 were directly assayed in the culture medium by specific immunoassays. As expected, IL-1 $\beta$ (2, 10, $100 \mathrm{pg} / \mathrm{ml}$ ) stimulated stromelysin synthesis and inhibited TIMP-1 production leading to an enhancement of stromelysin activity into culture supernatants. Inversely, TGF $\beta 1(10 \mathrm{ng} / \mathrm{ml})$ decreased stromelysin synthesis/activity and stimulated TIMP-1 production. Furthermore, TGF $\beta 1$ partially reversed
IL-1 $\beta$ effects on TIMP-1 and stromelysin synthesis and highly decreased stromelysin activity found in the culture medium. At therapeutic concentration, neither aceclofenac nor diclofenac nor $4-\mathrm{OH}$ aceclofenac were capable of modifying stromelysin synthesis/activity or TIMP- $1 \beta$ production. Furthermore, these drugs did not affect the TGF- $\beta 1$ induced effects. In vitro, IL-1 $\beta$ induced a profound disequilibrium between stromelysin and TIMP-1 synthesis leading to an increase of stromelysin activity found in the culture medium. This imbalance is partially corrected by TGF $\beta 1$ but not affected by aceclofenac and metabolites.

\section{Synthesis and evaluation of non-carboxylic pyridinic derivatives as cyclooxygenase inhibitors}

J.M. Dogné ${ }^{1}$, X. de Leval' ${ }^{1}, J$. Delarge ${ }^{1}$,

G. Deby' ${ }^{2}$, M. Mathy ${ }^{3}$, J. Chahboune ${ }^{3}$,

A. Labasse ${ }^{3}$, P. Neven ${ }^{1}$, F. Somers ${ }^{1}$, B. Pirotte ${ }^{1}$, J.Y. Reginster ${ }^{3}$ and Y. Henrotin ${ }^{3}$

${ }^{1}$ Department of Medicinal Chemistry,

University of Liège, 1 av. de I'Hôpital, tour 4 $(+5)$ Sart-Tilman; ${ }^{2}$ Centre for the Biochemistry of Oxygen, Institute of Chemistry, Sart Tilman; ${ }^{3}$ Bone and Cartilage Metabolism Research Unit, University Hospital, Sart-Tilman, CHU-B23, 4000 Liège, Belgium

Torasemide, a sulfonylurea pyridinic loop diuretic, emerged from the pharmacomodulation of an isomere of niflumic acid named triflocine. On the other hand, nimesulide, a nitrobenzenic sulfonamide which does not carry any carboxylic moiety has been described as COX-2 selective inhibitor. These two observations led us to design and test a series of non-carboxylic pyridinic derivatives for their inhibitory activity on cyclooxygenase. For this purpose, an enzymatic assay using purified COX-1 and COX-2 was set up. In this assay, one unit of cyclooxygenase enzyme (COX-1 or COX-2) was suspended in Tris buffer $(1 \mathrm{ml}, 100 \mathrm{mM}), \mathrm{pH}=8$, containing phenol $(2 \mathrm{mM})$ and hematin $(1 \mu \mathrm{M})$ as cofactors. They were preincubated with the substract alone (controls) or with drugs $(10 \mu \mathrm{M})$ for $5 \mathrm{~min}$ at $37^{\circ} \mathrm{C}$. Arachidonic acid sodium salt $(10 \mu \mathrm{M})$ was added and further incubated for $2 \mathrm{~min}$ at $37^{\circ} \mathrm{C}$. Reaction was halted by placing the tube on ice and by adding diclofenac sodium salt at a final concentration of $1 \mathrm{mM}$. $\mathrm{PGE}_{2}$ production was assayed by a specific radioimmunoassay (RIA). The effects of our molecules were compared with those of indomethacin and nimesulide. In our system, indomethacin $(10 \mu \mathrm{M})$ inhibited COX-1 by $17.1 \pm 1.2 \%$ and COX-2 by $31.2 \pm 3.3 \%$ (ratio COX-2/COX-1: 1.82 ) 
whereas nimesulide $(10 \mu \mathrm{M})$ inhibited specifically the production of $\mathrm{PGE}_{2}$ by $\mathrm{COX}-2$ by $75.5 \pm 2.1 \%$ (ratio COX-2/COX-1: 0.76). The compound JMD 11 showed a specific COX-2 inhibitory activity in the same order than nimesulide $(10 \mu \mathrm{M}$ : \% production of $\mathrm{PGE}_{2}$ using COX-1: 94.9 and using COX-2: 66.5; ratio COX-2/COX-1: 0.70). These data confirm the interest of non-carboxylic pyridinic structures as original COX-2 selective nonsteroidal anti-inflammatory drugs.

\section{Design, synthesis and pharmacological evaluation of original thromboxane receptor antagonists}

\author{
J.M. Dogné ${ }^{1}, X$. de Leval' ${ }^{1}$, J. Delarge ${ }^{1}$, \\ Y. Henrotin ${ }^{2}$, J.Y. Reginster' ${ }^{2}$, P. Neven ${ }^{1}$ \\ S. Rolin ${ }^{3}$ and B. Masereel ${ }^{3}$ \\ ${ }^{1}$ Department of Medicinal Chemistry, \\ University of Liège, 1 av. de I'Hôpital, tour 4 \\ $(+5)$ Sart-Tilman; ${ }^{2}$ Bone and Cartilage \\ Metabolism Research Unit, University Hospital, \\ Sart-Tilman; ${ }^{3}$ Department of Pharmacy, \\ University of Namur, 61 rue de Bruxelles, 5000 \\ Namur, Belgium
}

Since torasemide has been demonstrated to relax dose-dependently canine coronary precontracted by thromboxane $A_{2}$, a series of pyridinic and nitrobenzenic derivatives has been investigated with the aim to develop original thromboxane $A_{2}$ receptor antagonists. A nitrobenzenic sulfonylurea (BM 500), a pyridinic sulfonylcyanoguanidine (BM 144) and a nitrobenzenic sulfonylcyanoguanidine (BM 519) emerged as the most potent antagonists tested. Indeed, their affinity for human washed platelets thromboxane $\mathrm{A}_{2}$ receptors labelled with $\left[{ }^{3} \mathrm{H}\right] \mathrm{SQ}$ 29,548 has been determined (IC50: BM144: $0.28 \mu \mathrm{M}$; BM500: $0.079 \mu \mathrm{M}$; BM 519: $0.022 \mu \mathrm{M})$ and demonstrated to be higher than torasemide (IC50: $3.6 \mu \mathrm{M}$ ) and sulotroban $(0.76 \mu \mathrm{M})$. Their antagonism potency has been confirmed since we demonstrated that our drugs prevented human platelet aggregation induced by arachidonic acid, the biological precursor of thromboxane $\mathrm{A}_{2}$ (IC50: BM144: $9.0 \mu \mathrm{M}$; BM500: $14.2 \mu \mathrm{M}$; BM 519: $0.45 \mu \mathrm{M})$ and U-46619, a stable TXA $_{2}$ agonist (IC50: BM144: 12.9 $\mu \mathrm{M}$; BM500: $9.9 \mu \mathrm{M}$; BM 519: $0.15 \mu \mathrm{M})$. The three torasemide derivatives also relaxed rat aorta ring precontracted by U- 46619 . The calculated IC50 values (IC50: BM144: $0.12 \mu \mathrm{M}$; BM500: $0.19 \mu \mathrm{M}$; BM 519: 0.0012 $\mu \mathrm{M}$ ) showed that our drugs were much more active than torasemide (IC50: $>10 \mu \mathrm{M}$ ) and sulotroban (IC50: $1.62 \mu \mathrm{M}$ ). Moreover, in rats $(30 \mathrm{mg} / \mathrm{kg}$ per os), BM500, BM144 and BM519 have lost the diuretic properties of torasemide. These results indicate that our com- pounds can be considered as novel non-carboxylic thromboxane $A_{2}$ antagonists much more potent than sulotroban.

\section{Opposite effects of IL-10 and TNF $\alpha$ on the glucocorticoid sensitivity of human monocytes: Implications for anti-inflammatory therapies}

\section{Franchimont ${ }^{1,2,3}$, H. Martens ${ }^{2}$, E. Louis ${ }^{1}$, G.P. Chrousos ${ }^{3}$, J. Belaiche ${ }^{1}$ and V. Geenen ${ }^{2}$ ${ }^{1}$ Division of Gastroenterology; ${ }^{2}$ Laboratory of Radio-Immunology \& \\ Neuroendocrine-Immunology, Institute of Pathology CHU-B23, University of Liège-Sart Tilman; ${ }^{3} \mathrm{NICHD}$, NIH, Bethesda, MD, USA}

Introduction: Glucocorticoids are widely used in the treatment of inflammatory diseases, but patients sometimes developed glucoresistance during longterm steroid therapy. This study investigated the hypothesis that glucocorticoid sensitivity is modulated by cytokines involved in inflammatory processes.

Methods: We analysed the effects of dexamethasone (DXM) on IL-10 and TNF $\alpha$ secretions induced by LPS in human whole blood cell cultures. Then, the putative modulation of DXM sensitivity by preincubation with IL-10 or TNF $\alpha$ was investigated in LPSinduced IL-6 secretion by human whole blood cell cultures, as well as in PMA-elicited IL-1RA secretion by the human monocytic cell line U937. Finally, the influence of IL-10 and TNF $\alpha$ on DXM binding to U937 cells was evaluated using Scatchard analyses.

Results: DXM exerted distinct effects on LPSinduced IL-10 and TNF $\alpha$ secretions: while DXM suppressed TNF $\alpha$ in a dose-dependent fashion, its effect on IL-10 was biphasic with a stimulation of IL-10 at low doses, and with an inhibition at high doses. Pretreatment with IL-10 increased, while pre-treatment with TNF $\alpha$ diminished the ability of DXM to suppress IL-6 secretion induced by LPS in whole blood cell cultures $(p<0.01)$. Interestingly, DXM was found to increase the secretion of IL-1RA stimulated by PMA in U937 cells. Pre-treatment with IL-10 enhanced this effect, while TNF $\alpha$ inhibited it $(p<0.05)$. Finally, Scatchard analyses repeatedly evidenced that IL-10 increases $(p<0.001)$, whereas TNF $\alpha$ decreases the number of DXM binding sites in U937 cells, with no discernible effect on the binding affinity.

Conclusions: Glucocorticoids differentially modulate IL-10 and TNF $\alpha$ secretions in a LPS dosedependent fashion. Glucocorticoid sensitivity is altered by IL-10 and by TNF $\alpha$. The $\mathrm{Th}_{2}$ cytokine IL-10 synergically acts with glucocorticoids, while the proinflammatory cytokine TNF $\alpha$ blocks the effect of glucocorticoids. Since IL-10 increases and TNF $\alpha$ 
decreases glucocorticoid sensitivity of monocytes, this study provides evidence for specific steroidsparing effects of cytokine-directed therapies. (Supported by Fondation Léon Fredericq of Liège Medical School and by FNRS.)

\section{Evaluation of the antiinflammatory potency of nimesulide, aceclofenac and their metabolites on purified COX-1 and COX-2}

\author{
X. de Leval ${ }^{1}$, J.M. Dogné ${ }^{1}$, J. Delarge ${ }^{1}$, \\ G. Deby ${ }^{2}$, M. Mathy ${ }^{3}$, J. Chahboune ${ }^{3}$, \\ A. Labasse ${ }^{3}$, P. Neven ${ }^{1}$, F. Somers ${ }^{1}$, \\ J.Y. Reginster ${ }^{3}$ and Y. Henrotin ${ }^{3}$ \\ ${ }^{1}$ Department of Medicinal Chemistry, \\ University of Liège, 1 av. de I'Hôpital, tour 4 \\ $(+5)$ Sart-Tilman; ${ }^{2}$ Centre for the Biochemistry \\ of Oxygen, Institute of Chemistry, Sart Tilman; \\ $4000{ }^{3}$ Bone and Cartilage Metabolism Research \\ Unit, University Hospital, Sart-Tilman, \\ CHU-B23, 4000 Liège, Belgium
}

Evidence of the existence of two forms of cyclooxygenase and the clinical relevance of COX-2 activities has led to the development of COX-2 selective NSAIDs. In order to evaluate this selectivity, we have developed and validated an enzymatic method. In this assay, one unit of cyclooxygenase enzyme (COX-1 or COX-2) was suspended in Tris buffer $(1 \mathrm{ml}, 100 \mathrm{mM})$, $\mathrm{pH}=8$, containing phenol $(2 \mathrm{mM})$ and hematin $(1 \mu \mathrm{M})$ as cofactors. They were preincubated with the substract alone (controls) or with nimesulide or indometacin $(0.01$ to $100 \mu \mathrm{M})$ for $5 \mathrm{~min}$ at $37^{\circ} \mathrm{C}$. Arachidonic acid sodium salt $(10 \mu \mathrm{M})$ was added and further incubated for $2 \mathrm{~min}$ at $37^{\circ} \mathrm{C}$. Reaction was halted by placing the tube on ice and by adding diclofenac sodium salt at a final concentration of $1 \mathrm{mM} . \mathrm{PGE}_{2}$ production was assayed by a specific radioimmunoassay (RIA). Using this test, we have evaluated the antiinflammatory potency and the selectivity of nimesulide (NIM), aceclofenac (ACE) and their main metabolites: $4-\mathrm{OH}$ nimesulide $(4-\mathrm{OH}$ NIM), 4-OH aceclofenac (4-OH ACE) and diclofenac (DIC). Nimesulide did not inhibit the $\mathrm{PGE}_{2}$ production by COX-1 but dose-dependently decreased COX-2 activity. In contrast, ACE and DIC caused a dosedependent inhibition of both COX-1 and COX-2 (ACE; $\mathrm{IC}_{50}$ superior to $100 \mu \mathrm{M}$ on COX-1 and COX-2; DIC: $\mathrm{IC}_{50}=0.79 \mu \mathrm{M}$ on COX-1 and $1.04 \mu \mathrm{M}$ on COX-2). Finally, we have observed that hydroxylated nimesulide and aceclofenac fully lost their activities on COX1 and COX-2. In conclusion, nimesulide appears to be the only COX-2 selective drug investigated in this study. Moreover, it appears that hydroxylated metabolites of nimesulide and aceclofenac were inactives on both COX-1 and COX-2.
Comparative effects of nimesulide, nimesulide L-lysine and nimesulide L-lysine L-arginine on human articular chondrocytes in vitro

X. de Leval'1 , J.M. Dogné11, J. Delarge',

B. Pirotte ${ }^{1}$, G. Deby ${ }^{2}$, M. Mathy ${ }^{3}$,

J. Chahboune ${ }^{3}$, A. Labasse ${ }^{3}$, P. Neven',

J.Y. Reginster ${ }^{3}$ and Y. Henrotin ${ }^{3}$

${ }^{1}$ Department of Medicinal Chemistry,

University of Liège, 1 av. de I'Hôpital, tour 4

(+5) Sart-Tilman; ${ }^{2}$ Centre for the Biochemistry of Oxygen, Institute of Chemistry, Sart Tilman;

${ }^{3}$ Bone and Cartilage Metabolism Research Unit, University Hospital, Sart-Tilman, CHU-B23,

4000 Liège, Belgium.

Nimesulide L-lysine and nimesulide L-lysine L-arginine are two derivatives which present a better water solubility than nimesulide $(0.01 \mathrm{mg} / \mathrm{ml}$ for nimesulide, $7.5 \mathrm{mg} / \mathrm{ml}$ for nimesulide L-lysine). Therefore, those two drugs should present a more favorable pharmacokinetic profile than nimesulide. So, it seemed to us important to compare the effects of these three drugs on IL-6, IL- 8 , prostaglandins $\mathrm{E}_{2}$ and proteoglycans production by human chondrocytes in vitro. The chondrocytes were enzymatically isolated and cultured for 72 hours in the absence or presence of IL-1 $\beta$ ( 5 units) and with or without the investigated drugs. Specific radioimmunoassays were used to quantify proteoglycan and $\mathrm{PGE}_{2}$ production. Cytokine production (IL-6 and IL-8) was assayed by Enzyme Amplified Sensitivity Immunoassays (EASIAs). DNA, proteoglycans and IL-8 productions were not significantly different for the three drugs. In contrast, IL6 levels measured for the nimesulide L-lysine L-arginine were significantly lower than those measured for the two other drugs. In conclusion, these two nimesulide derivatives showed better pharmacokinetic properties but also similar, even better pharmacological profile than nimesulide.

\section{Induction of inducible nitric oxide synthase, cyclooxygenase- 2 and interleukin-1 $\beta$ expression by lipopolysaccharide in human chondrocytes}

M. Mathy-Hartert ${ }^{1}, J^{\prime}$ Chahboune ${ }^{1}$, A. Labasse ${ }^{1}$, G. Deby ${ }^{2}$, X. de Leval ${ }^{3}$, J. Delarge ${ }^{3}$, J.-M. Dogne ${ }^{3}$, J.-M. Crielaard' ${ }^{1}$, J.-Y. Reginster ${ }^{1}$ and Y. Henrotin ${ }^{1}$, ${ }^{1}$ Bone and cantilage Metabolism Research Unit; ${ }^{2}$ Center for Oxygen Biochemistry, ${ }^{3}$ Department of Medicinal Chemistry (3), University of Liège, Belgium

Studies involving animal arthritis models and analysis of human synovial fluid have implicated nitric oxide $(\mathrm{NO})$, prostaglandins (PG) and interleukin-1 $\beta$ (IL-1 $\beta$ ) 
in the pathogenesis of rheumatoid arthritis and osteoarthritis. Moreover, these three mediators were reported to trigger cartilage degradation, suggesting their roles in the pathophysiology of joint diseases. Inducible isoenzymes, nitric oxide synthase (iNOS) and cycloox ygenase-2 (COX-2) account for high levels of, respectively, NO and PGs generation. The objective of the present study was to examine mRNA expression of iNOS, COX-2 and IL-1 $\beta$ in human articular chondrocytes isolated from cartilage obtained from donors without known history of joint diseases.

Human chondrocytes were cultured for 48 hours in the absence or presence of lipopolysaccharide (LPS) $(10 \mu \mathrm{g} / \mathrm{ml})$. Following treatment of cells and ex traction of RNA, semi quantitative Reverse Transcription Polymerase Chain Reaction (RT PCR) was used to examine expression of the iNOS, COX-2 and IL- $1 \beta$ genes. Expression was standardized by concomitant amplification of an endogenous housekeeping gene $(\beta$-actin $)$. For amplification of the desired cDNA, genespecific primers were used. Amplified cDNA were resolved by agarose electrophoresis and quantifications were evaluated by densitometry (Gel Doc 2000, Bio Rad). The specificity of amplified band was valided by their predicted size.

Under basal condition, both iNOS and COX-2 mRNA were present at low level (150 and 256 Densitometry Units (DU), respectively) while IL-1 $\beta$ mRNA was undetectable. Expression of the three genes were markedly increased by treatment with LPS (iNOS: 831 DU, COX-2: 1017 DU, IL-1 $\beta: 427$ DU). These data indicate a major role for control of NO, $\mathrm{PGE}_{2}$ and IL1- $\beta$ synthesis at the mRNA levels.

\section{Critical role of IL-4 and IL-5 in acute and chronic rejection of MHC class-II incompatible skin grafts}

\section{A. Le Moine ${ }^{1}$, M. Surquin ${ }^{1}$, F.X. Demoor ${ }^{1}$, V. Flamand ${ }^{1}$, M.-A. Nahori ${ }^{2}$, M. Pretolani ${ }^{* 3}$, M.Y. Braun ${ }^{1}$, R. Kiss ${ }^{1}$, M. Goldman ${ }^{1}$ and D. Abramowicz'}

${ }^{2}$ Hopital Erasme, Brussels, Belgium; ${ }^{2}$ INSERM Unité $485^{*}$, Institut Pasteur; ${ }^{3}$ INSERM Unité 408* ${ }^{*}$ Xavier Bichat, Paris, France

Skin grafts from MHC class II antigen disparate bm 12 mice are acutely rejected by untreated C57BL/6 mice. If acute rejection is prevented by injections of an anti$\mathrm{CD} 3 \mathrm{mAb}$, the bm12 grafts will undergo chronic rejection which is characterized by a proliferative intimal vasculopathy and a dermal fibrosis. In both settings, rejected allografts display increased amounts of IL- 4 and IL-5 mRNA, together with a massive eosinophil infiltration. MLR revealed that in both cases, recipients were primed for IL 4 and IL-5 production. The aim of our study is to investigate the pathogenic role played by IL-4 and IL-5 in acute and chronic allograft rejection, since these Th2-type cytokines are crucial for eosinophil-mediated pathology.

For the study of acute rejection, we performed bm 12 skin grafts on IL-4 and IL-5-deficient C57BL/6 mice. Graft rejection was significantly delayed on both types of cytokine-deficient mice. IL-4 or IL5-deficiency resulted in the lack of graft eosinophil infiltration. The rejection that still occurred in the majority of IL-4- and IL-5-deficient mice was likely to be mediated by CD4 cytotoxicity, which is due to Fas/ Fas ligand interactions. The possible independent role of IL-5 and eosinophils in triggering acute allograft rejection was therefore investigated in MHC class II disparate donor-recipient strains unable to establish Fas/Fas ligand interactions. Fas ligand-deficient $\mathrm{gld} /$ gld mice rejected bm 12 skins and bm 12 mice rejected Fas-deficient $l p r / l p r$ C57BL/6 skins. Neutralization of IL-5 prevented graft eosinophil infiltration and acute rejection in both combinations, indicating that IL-5 and eosinophils constitute a pathway intrinsically sufficient to mediate rejection of MHC class II disparate skin allografts.

With regard to chronic bm 12 skin allograft rejection, neutralization of IL -4 completely prevented allograft vasculopathy as well as graft eosinophil infiltration and interstitial fibrosis. Injections of antiIL- $5 \mathrm{mAb}$ or the use of IL-5-deficient mice as recipient prevented eosinophil infiltration and dermal fibrosis but not vasculopathy.

In conclusion, (1) MHC class II disparate skin allografts trigger an IL-4 and IL-5-dependent infiltration of eosinophils that is sufficient to induce acute graft destruction; (2) with respect to chronic rejection, IL-4-and IL-5-mediated allograft eosinophil infiltration is associated with interstitial fibrosis. IL-4, but not eosinophils, is required for obliterative graft vasculopathy.

\section{Chelating and antiradical properties of anti-inflammatory drug nimesulide: chemiluminescence and EPR study}

\section{Ange Mouithys-Mickalad', Ginette Deby-Dupont ${ }^{1,2}$, Carol Deby ${ }^{1}$, Maurice Lamy ${ }^{1,2}$ and Yves Henrotin ${ }^{2,3}$} ${ }^{1}$ Center for Oxygen Research \& Development (CORD), Institut de Chimie, B6a; ${ }^{2}$ Department of Anesthesiology and Intensive Care, B35; ${ }^{3}$ Cartilage and Bone Research Unit (UROC), Institut de Pathologie, B 35, University of Liège, Sart Tilman, 4000 Liè, Belgium

Several studies have been focused on the antioxidant properties of the non steroidal anti-inflammatory 
drug Nimesulide (2-phenoxy-4-nitro-methansulfonanilide; NIM) and other sulfanilamide-related antiinflammatory compounds. NIM was reported to scavenge both hydroxyl radical $(\bullet \mathrm{OH})$ and superoxide anion $\left(\mathrm{O}_{2} \dot{-}\right)$, but the mechanism by which NIM and its main metabolite (OH-NIM) exert their antioxidant activity remains to be discussed. It is also know $n$ that the synovial fluid from rheumatoid arthritis (RA) patients can contain measurable amounts of iron capable of catalyzing oxidative damage in vivo, and that the iron status of RA patients influences the disease pathology. This study was designed to understand the mechanism of the antioxidant activity of NIM and HO-NIM. Nimesulide and OH-NIM were tested (by chemiluminescence technique, CL) for their ability to react with hypochlorous acid ( $\mathrm{HOCl})$ in vitro, and compared to phenylbutazone (PBZ). The effects of NIM and HO-NIM were also tested by electron paramagnetic resonance technique (EPR) on 3 free radical species: the ascorbyl free radical (AFR) that is formed spontaneously in plasma, and ${ }^{\circ} \mathrm{OH}$ and $\mathrm{O}_{2}{ }^{\circ-}$ radicals produced in vitro. NIM, HO-NIM and $\mathrm{PBZ}$ scavenged $\mathrm{HOCl}$ at a rate sufficient to decrease light emission $(45,85$ and $62 \%$ inhibition, respectively). The range of efficacy was HO-NIM > PBZ > NIM. Nimesulide decreased the EPR signal intensity of ${ }^{\circ} \mathrm{OH}$, but not $\mathrm{O}_{2}-$. HO-NIM exerted a good scavenging effect towards both radical species. The CL of stimulated neutrophils was decreased by NIM ( 5 to $25 \mu \mathrm{g} / \mathrm{ml})$ in a dose-dependent manner. The spontaneous AFR from plasma of healthy volunteers was reduced with $10^{-4} \mathrm{M}$ NIM and HO-NIM. However, when plasma was overloaded with $10^{-4} \mathrm{M}$ ascorbate, the resulting AFR signal intensity was increased by NIM, an observation that could be explained by modification of the redox status of plasma by iron scavenging by NIM, what would hinder the function of ascorbate oxidase cycle. These results demonstrated that NIM exerts its antiradical properties, mainly by chelating metal iron. OH-NIM shared similar properties with NIM. NIM thus present beneficial antioxidant effects at clinically relevant concentrations in pathological situations like rheumatoid arthrisis.

\section{Nitrated proteins as an indicator of an oxidative activity in bronchoalveolar lavage fluid of intensive care patients}

\author{
M. Nys, M. Mathy-Hartert, P. Damas, \\ G. Deby-Dupont and M. Lamy
}

Department of Anaesthesiology and Intensive

Care \& Centre for Oxygen Research and Development, University of Liège, Belgium

Invasion of lungs by neutrophils is a common phenomenon in intensive care patients with ven- tilator-associated pneumonia (VAP) and with acute respiratory distress syndrome (ARDS). These neutrophils are activated and degranulate in situ. They produce nitric oxide (NO) as a defense mechanism and reactive oxygen species during their respiratory burst. The simultaneous presence of $\mathrm{NO}$ and superoxide anion can lead to the in situ formation of peroxynitrite (ONOO-), a potent oxidant species responsible for cell damage and protein nitration. In 71 bronchoalveolar lavage (BAL) fluids of 58 patients ( 42 males, 16 females; mean age: $55 \pm 17$ years) at risk of VAP, we measured the concentrations of nitrated proteins (NTP) and active myeloperoxidase (MPO) as a marker of neutrophil degranulation, and correlated them with the presence of activated neutrophils. The effects of BAL fluid on human alveolar cells (A549) in culture were analyzed by measuring the release of ${ }^{51} \mathrm{Cr}$ pre-incorporated by the cells (cytotoxicity test) and correlated with NTP and MPO values. Pearson's correlation and Mann-Whitney test were performed, with $p<0.05$ being significative.

VAP and/or ARDS were diagnosed in 38 patients (VAP/ARDS group), and 20 patients without these pathologies formed the control group. No significative difference was observed between the 2 groups for clinical parameters (mean APACHE II score 15.85 \pm 5.49 ; mean intubation duration: $19.93 \pm 15.49$ days; mean ICU stay: $29.45 \pm 23.99$ days; 17 deaths). There was no significative difference in the mean protein value of BAL between the 2 groups $(1.49 \pm 0.17 \mathrm{mg} / \mathrm{ml}$ in VAP/ARDS versus $1.38 \pm 0.34$ in controls). A significative difference was found for the mean values of neutrophil count $\left(1.21 \pm 0.35 .10^{6}\right.$ cells $/ \mathrm{ml}$ in VAP/ARDS versus $0.18 \pm 0.11 .10^{6}$ in controls; $p<0.005)$, NTP $(13.50 \pm 3.80 \mu \mathrm{g} / \mathrm{ml}$ in VAP/ ARDS versus $0.8 \pm 0.4$ in controls; $p<0.05)$ and MPO $(1.66 \pm 0.45 \mathrm{U} / \mathrm{ml}$ in $\mathrm{VAP} / \mathrm{ARDS}$ versus $0.25 \pm 0.1$ in controls; $p<0.005$ ), and for cytotoxicity (IC: cytotoxicity index expressed in $\% 51 \pm 15 \%$ in VAP/ ARDS versus $8.7 \pm 1.3$ in controls; $p<0.01$ ). The presence of NTP in BAL correlated with the number of neutrophils $(p<0.001)$ and with the presence of active MPO $(p<0.001)$, but none of these parameters correlated with total proteins. The cytotoxicity of BAL was correlated with the values of NTP $(r=0.92 ; p<0.001)$ and MPO $(r=0.88$; $p<0.001)$.

From these data, we concluded that MPO was released in the alveoli by activated ne utrophils and that NTP were formed in situ in relation with the oxidant activity of stimulated neutrophils. This intraalveolar oxidant activity led to the production of BAL fluids which were cytotoxic on alveolar cells. The presence of NTP in BAL could thus be an indicator of an in situ oxidative activity occurring in patients with VAP/ARDS. 
Critical role of IL-4, IL-5 and eosinophils in the acute skin graft rejection induced by B2 microglobulin-associated minor transplantation antigens

\section{Surquin ${ }^{1}$, A. Le Moine ${ }^{1}$, FX. Demoor ${ }^{1}$,} V. Flamand ${ }^{1}$, M.A. Nahori ${ }^{2}$, M. Pretolani ${ }^{2}$ M. Goldman ${ }^{1}$ and D. Abramowicz ${ }^{1}$

${ }^{1}$ Hôpital Erasme, Université Libre de Bruxelles, ${ }^{2}$ INSERM U408, CHU Bichat, Paris, France

Minor transplantation antigens are constituted by the association of an MHC class I or class II molecule with a peptide derived from a protein which displays allotypic differences between the donor and the recipient. $\beta 2$ microglobulin $(\beta 2 \mathrm{~m})$ peptides are constitutively present in the MHC class I and II molecules. These antigenic complexes represent transplantation antigens in mice as indicated by the rejection of $\beta 2 \mathrm{~m}$-positive grafts by genetically $\beta 2 \mathrm{~m}$ deficient mice. The immunological mechanisms triggering the rejection of minor transplantation antigens are still poorly understood.

We performed skin grafts from wild-type C57BL/ $6(\beta 2 \mathrm{~m}+/+)$ mice on $\mathrm{C} 57 \mathrm{BL} / 6 \quad \beta 2 \mathrm{~m}$ deficient $(\beta 2 \mathrm{~m}-/-)$ mice. Ninety-three $\%$ of $\beta 2 \mathrm{~m}-/-$ mice $(N=21)$ rejected their graft within 20 days after transplantation. Histological examination of rejected grafts showed tissue necrosis and infiltration by numerous eosinophils (eosinophils $/ 0.0025 \mathrm{~mm}^{2} .36$ versus 2 in syngeneic grafts, $P<0.0001)$. In vitro, lymph node $\mathrm{T}$ cells from $\beta 2 \mathrm{~m}-/-$ sensitized mice produced large amounts of IL-5 when stimulated with $\beta 2 \mathrm{~m}+/+$ cells. Furthermore, IL-5 and IL- 4 mRNA were detected by RT-PCR within rejected $\beta 2 \mathrm{~m}+/+$ grafts, but not in syngeneic skins. To investigate the possible causal role of IL- 4 and IL-5 in the rejection of $\beta 2 \mathrm{~m}+/+$ grafts, we performed in vivo experiments with neutralizing anti-IL- 4 and anti-IL-5 mAb. Treatment with either mAb significantly prolonged $\beta 2 \mathrm{~m}+/+$ skin graft survival (\% of graft survival at 1 month: anti-IL-4, 90\%, anti-IL-5, $62 \%$; versus $7 \%$ in the untreated group; $P<0.001$ and $P<0.01$, respectively). Both treatments also prevented the allograft infiltration by eosinophils.

We conclude that IL-4 and IL-5 play a crucial role in the rejection of $\beta 2$ m-associated minor transplantation antigens, probably by mediating allograft destruction by eosinophils. 


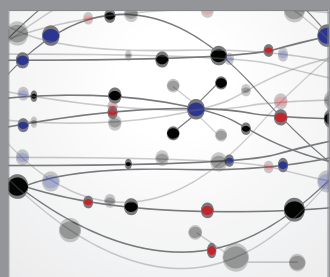

The Scientific World Journal
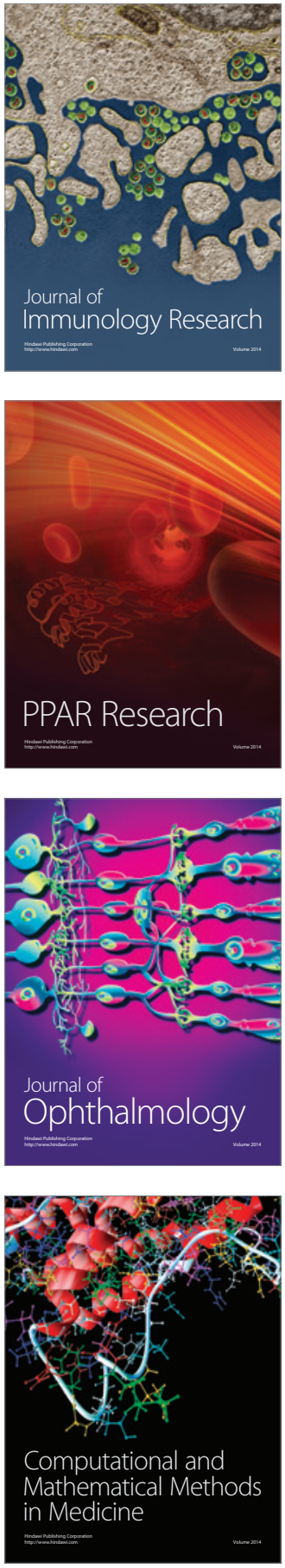

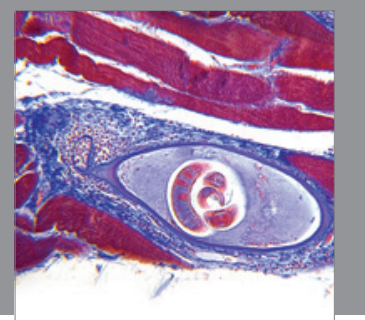

Gastroenterology

Research and Practice
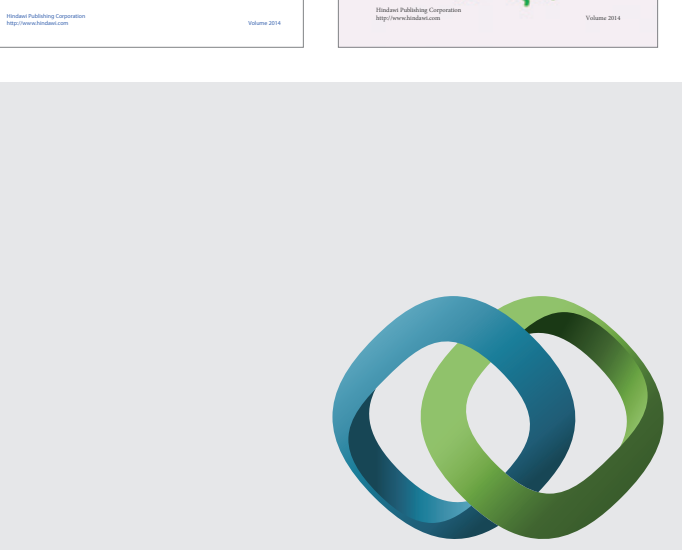

\section{Hindawi}

Submit your manuscripts at

http://www.hindawi.com
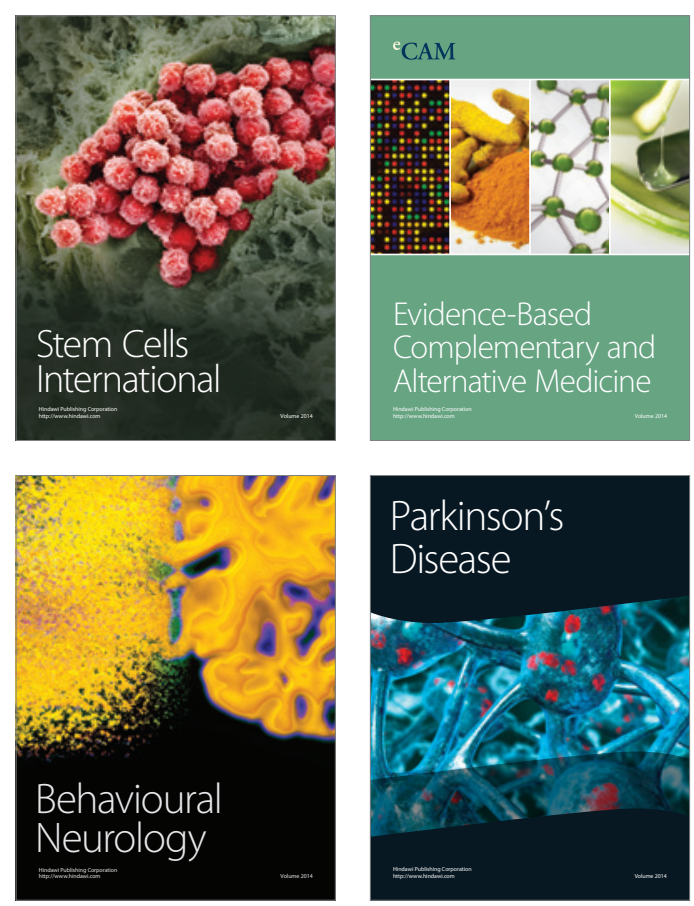

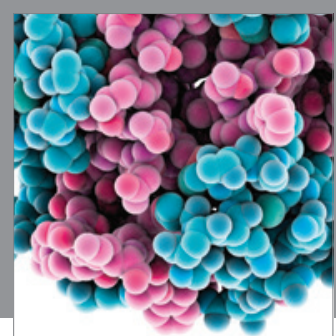

Journal of
Diabetes Research

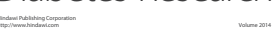

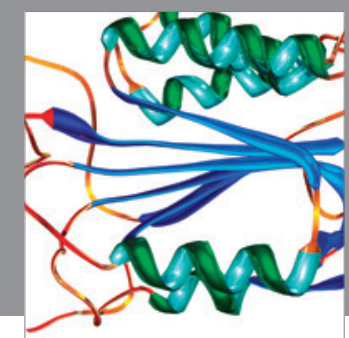

Disease Markers
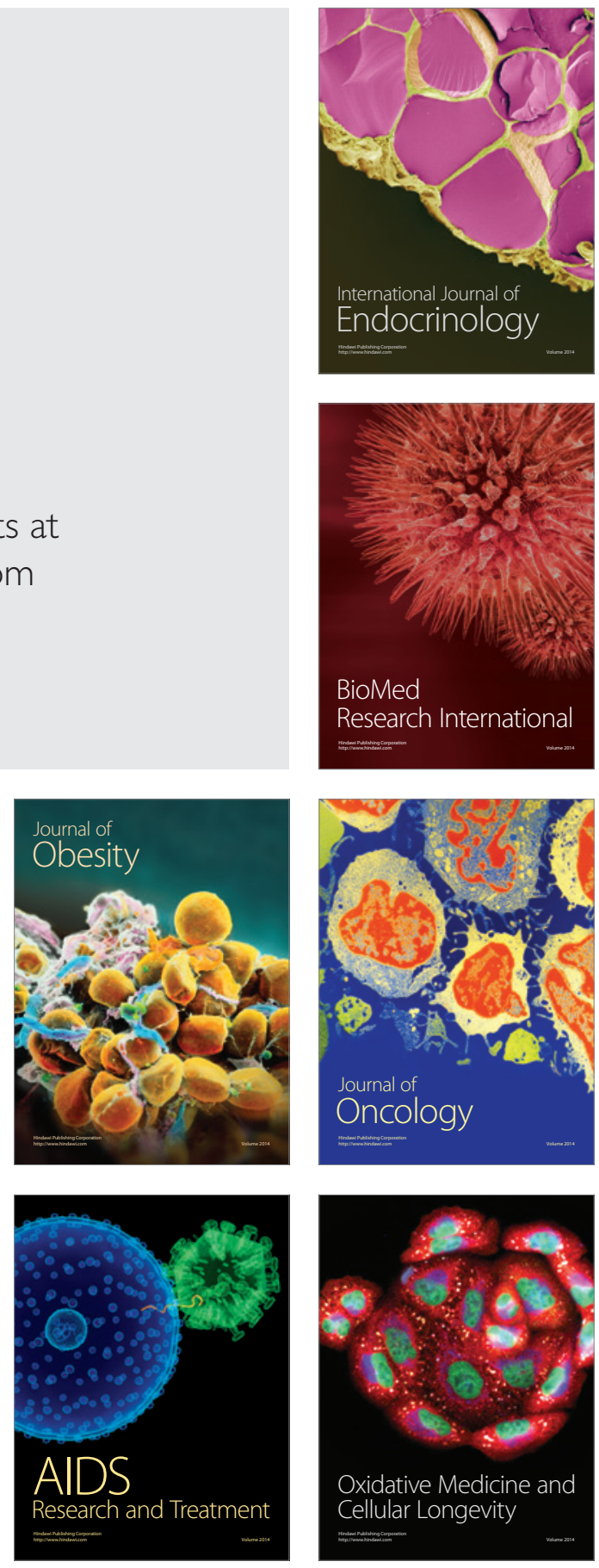